UDK $784 \$ 3(497.12)$ Ipavec B.

\title{
NEKAJ ZNAČILNOSTI SAMOSPEVOV BENJAMINA IPAVCA
}

\author{
Manica špenda 1 (Maribor)
}

Glavno ustvarjalno področje Benjamina Ipavca je bila vokalna glasba, ki se ji je posvečal ves čas svojega skladateljskega delovanja. To je razumljivo glede na slovensko pevsko ljudsko tradicijo in na dobo, ki je terjala zlasti vokalna dela. $\mathrm{V}$ tem okviru je skladatelj razvil svoje ustvarjalne dispozicije in kompozicijsko znanje predvsem $\mathrm{v}$ samospevih. $\mathrm{V}$ njih je vidno njegovo hotenje po prenosu dosežkov evropskega romantičnega samospeva v slovensko glasbo, pri čemer se je v največji meri naslanjal na tekste slovenskih avtorjev. Očitna je tudi tendenca skladatelja, da prebije ozek okvir tedanje dobe, $v$ katerem je bila glasba predvsem sredstvo za prebujanje nacionalne zavesti in domoljubnih custev. $\mathrm{V}$ tem pogledu ima Ipavec velike zasluge za dvig slovenske glasbene kulture $\mathrm{v}$ tej razvojni fazi.

Skladbe, ki jih obravnava ta prispevek, so nastale $\mathrm{v}$ zadnjih letih Ipavcevega ustvarjanja, torej $\mathrm{v}$ času, ko si je skladatelj že izdelal svoj način izražanja in prešel $\mathrm{v}$ żađnjo fazo romantičnega stila. ${ }^{1}$

Samospev Pozabil sem mnogokaj dekle, na tekst Josipa Murna Aleksandrova, je prikupen, s pristno lirično romantičnim razpoloženjem. Osnovna tonaliteta je es-dur. Formalno je zgrajen iz štirih taktov klavirskega uvoda, ki je zasnovan na ležečem basu in lepo uvaja omenjeno razpoloženje. Uvodu sledijo trije deli po deset taktov in ob sklepu štirje takti klavirske poigre. Drugi del je $\mathrm{v}$ melodičnem in harmonskem pogledu ponovitev prvega; majhna melodična in harmonska sprememba je le ob sklepu drugega dela. Ritem je zaradi stopnjevanja izpeljan nekoliko drugače: $\mathrm{v}$ prvem delu je osminsko gibanje, medtem ko $\mathrm{v}$ drugem delu nastopajo triole.

že v prvem delu je očitno, da je skladatelj skušal kar najbolj slediti vsebini teksta, ne da bi pri tem zanemaril muzikalno formalni potek skladbe. Harmonsko je $\mathrm{v}$ tem delu uporabil naslednje postope: $\mathrm{v}$ 8. taktu je trozvok v c-molu, ki je obenem subdominanta g-mola, $\mathrm{v}$ katerega modulira. V 11. taktu začenja melodično in harmonsko stopnjevanje, ki vodi

${ }^{1}$ Prim. Cvetko D., ME, 1974, II, 221; Ob odkritju spomenikov skladateljem Ipavcem, 1972, 17. 
v 13. taktu do akordičnih tvorb na dominanti c-mola, $v$ katerega preide na višku melodičnega stopnjevanja, ki je podkrepljeno tudi $\mathrm{z}$ dinamično oznako forte; sledi prehod $\mathrm{v}$ dominanto b-dura $\mathrm{s}$ prehitkom $\mathrm{v}$ b-duru ( $\mathrm{v} 14$. taktu). Trozvok na toniki b-dura je obenem dominanta osnovne tonalitete, es-dura. Prehod poudari skladatelj še z dominantnim septakordom. Na zadnji četrtinki 14. takta začenja drugi del skladbe, ki je - kot že omenjeno $-\mathrm{v}$ melodičnem in harmonskem pogledu enak prvemu delu, $\mathrm{z}$ izjemo zadnjih treh taktov. Drugi del sklene skladatelj $\mathrm{s}$ kadenco v b-duru v 23. taktu. Na zadnji četrtinki 24. takta začenja tretji del samospeva in sicer $\mathrm{v}$ ges-durovi tonaliteti, $\mathrm{v}$ katero preide $\mathrm{z}$ mediantno zvezo $(24 . \mathbf{2 5}$. takt). V 26. taktu je tiskovna napaka, kajti $\mathrm{v}$ melodiji bi moral biti ces in ne c. $\mathrm{V}$ istem taktu nastopi kromatični korak $\mathrm{v}$ ces-dur in nato $\mathrm{v}$ cesmol, kateremu sledi v 27. taktu kadenca na ležeči kvinti v ges-duru. V 29. taktu je kratek izmik $\mathrm{v}$ b in es-mol. $\mathrm{V}$ presledku od 30. do 33. takta skladatelj domiselno ponovno prehaja $\mathrm{v}$ osnovno tonaliteto $-\mathrm{v}$ es dur, in sklene tretji del $\mathrm{v} 34$. taktu $\mathrm{s}$ kadenco na toniki es-dura. Zadnji štirja takti poigre so po tematiki in harmonski obdelavi sorodni klavirskemu uvodu in tako pripomorejo $\mathrm{k}$ celovitosti skladbe. Zadnji del je prav tako melodično soroden $\mathrm{s}$ prvima dvema, le harmonsko je nekoliko bogatejši: $\mathrm{v}$ njem nastopa več modulacij oz. izmikov. Samospev ima formalno torej le en desettaktni del, ki se $\mathrm{z}$ opisanimi spremembami ponavlja, seveda na različno besedilo, vendar pa je začetek pri vseh treh kiticah isti: "pozabil sem mnogokaj dekle», kar skladatelju narekuje kitično formo.

Samospev Pozabil sem mnogokaj dekle odlikuje izdatna melodična invencija in pestra harmonska zasnova, ki ustrezno podčrtava osnovno razpoloženje in temelji na alteriranih akordih ter kromatičnih modulacijăh in izmikih. Skladba odraža muzikalno razgledanost avtorja, ki mu očitno ni bila tuja uporaba romantične kromatike. Interpretacija samospeva je za pevca zahtevna, vendar $\mathrm{mu}$ je $\mathrm{v}$ veliko oporo klavirska spremljava, $\mathrm{kl}$ je tako izdelana, da jo je mogoče izvajati tudi samostojno. Le mestoma moremo ugotoviti nedosledno vodenje glasov: npr. v 8., 13., 14. in 18. taktu izostane en glas, medtem ko se zdi, da je v 23. taktu en glas odvec. Omenjene pripombe pa niso tako bistvene, da bi zmanjševale vrednost te skladbe.

Samospev Mak žari, ki je na tekst Cvetka Golarja, je prav tako pristno romantičen. $\mathrm{V}$ njem prevladuje za romantiko značilna melodična in harmonska gradnja in tudi izrazna sredstva so $\mathrm{v}$ tem načinu: stranske dominante in $\mathrm{s}$ temi povezani kromatični vodilni in menjalni toni $\mathrm{v}$ melodiji. Napisan je $\mathrm{v}$ h-curu in začne $\mathrm{z}$ dvema talstoma klavirske predigre, ki je zgrajena na ostinatnem basu; pevski del začne $\mathrm{v}$ tretjem taktu in razvija glasbeno misel $\mathrm{v}$ smislu besedila $\mathrm{s}$ primernim dinamičnim stopnjevanjem od $\mathrm{p}$ do ff do 20. takta, kjer je sklep prvega dela. $\mathrm{V} 22$. taktu nastopi repriza $\mathrm{v} p$, $\mathrm{ki}$ do 28 . takta - ustrezno $\mathrm{z}$ besedilom - prinasa posamezne motive prvega dela ob primernem dinamičnem stopnjevanju (od $\mathrm{p}$ do ff). $\mathrm{V}$ 28. taktu skladatelj sklene pevski del samospeva in sicer $\mathrm{z}$ nepopolno kadenco na toniki osnovne tonalitete, $\mathrm{v}$ terčni legi, tako da sklep bolj izzveni kot zaključi, kar pa se lepo prilega vprašanju ob sklepu 
pevskega dela: «kje, kje si dekle moje, ti!«. Tudi dva takta klavirske poigre, ki sta motivično sorodna $\mathrm{z}$ uvodnima taktoma, to potrjujeta.

V harmonskem oziru je samospev bogat in pisan: skladatelj uporablja različne alteracije, zlasti $\mathrm{v}$ smislu menjalnih tonov. $\mathrm{S}$ harmonskega vidika bi skladbo lahko razdelili tudi takole: prvi del je sestavljen iz osmih taktov v osnovni tonaliteti - h-duru, ki so zgrajeni na ostinatem basu $\mathrm{Z}$ devetim taktom začenja drugi del $\mathrm{v}$ fis-durovi tonaliteti (dominanti osnovnega tonovskega načina), ki jo $\mathrm{v}$ prejšnjem taktu pripravi $\mathrm{s}$ tonom eis. Drugi del je harmonsko sestavljen iz trikrat po štiri takte; prvi stirje so v fis-duru, drugi štirje $\mathrm{v}$ istoimenskem molu - fis-molu, v 16. taktu je znižana druga stopnja, kar spominja na neapolitanski sekstakord; $v$ tretji skupini štirih taktov prehaja skladatelj v cis-durovo tonaliteto, $\mathbf{s}$ katero drugi del tudi sklene. Sicer uporablja $\mathrm{v}$ tem delu alterirane akordie in alterirane harmonsko tuje tone, vendar $\mathrm{v}$ prvih štirih taktih bistveno ne odstopa od fis-durove tonalitete, kar potrjuje tonalni odnos: prvi del tonika, drugi del (9-12 takt) dominanta, $v$ 13. in 14. taktu se skladatelf dotakne gis-mola (dvojne dominante fis-dura), v 16. taktu a-dura, v 17. taktu preide $\mathrm{v}$ cis-mol, ki tvori pripravo za prehod $\mathrm{v}$ istoimenski cis-dur, s katerim, kot že omenjeno, drugi del konč. Sledi prehod preko g-dura v h-mol, s katerim začne tretji, sklepni del samospeva, ki je sestavljen iz dvakrat po stirih taktov $\mathrm{z}$ dodatkom dveh taktov $\mathrm{v}$ h-duru. Harmonska shema je potemtakem: h-dur (tonika), fis-dur (dominanta), gis-mol (to nicna paralela), cis-dur (dvojna dominanta), h-mol, g-dur, h-dur z bogato uporabo septakordov in nonakordov.

Značilno za ta samospev je to, da $v$ njem ni težišča na melodični lintji, ampak na romantičnem harmonskem stavku, ki je izdelan zlasti $v$ klavirski spremljavi. Pevski del samospeva je sestavljen iz kratkih motivov, ki jih klavirska spremljava dopolnjuje. Evidentno je skladatelj tudi tu kompozicijsko sledil vsebini teksta oz. njegovemu lirično-romantičnemu razpoloženju, kar mu je tudi uspelo. $V$ tem samospevu je posebno dovršena klavirska spremljava, kar je v korist celotni formalni shemi samospeva, ki je jasna in logična: ABA; enako kot drugi skladateljevi samospevi odkriva tudi ta izrazito disponiranost avtorja za celovitost glasbene forme.

Med pesniki, ki so bili B. Iravcu custveno blizu, je bil tudi Anton Aškerc, ${ }^{2}$ na čigar tekst je napisal samospev Ciganka Marija. Ta začne s Stirimi takti klavirskega uvoda $\mathrm{v}$ h-molu, za katerega so značilni dvojni zadržki in motiv predtakta, ki prehaja iz gornjega $\mathrm{v}$ spodnji glas. V drugem in tretjem taktu sledi kratek izmik $v$ g-dur, t.j. $v$ subdominantno paralelo osnovne tonalitete $z$ zadržkom na znižani VI. stopnji (Tp) g-dura. Po kratkem izmiku nastopi $v$ 4. taktu spet osnovna tonaliteta; $v$ 3. taktu predigre zasledimo $\mathrm{v}$ kombinaciji tonov obrise ciganske lestvice $\mathrm{h}$ cis $d$ eis $f i_{3} g$ ais $\mathrm{h}$, pri čemer skuša skladatelj že v samem uvodu podčrtati osnovno vsebinsko misel in ustvariti določeno razpoloženje. $\mathbf{S}$ kadenco na dominanti h-mola, v 4. taktu, ki pa je v melodičnem h-molu (gis-eis),

${ }^{2}$ Kot avtor teksta je omenjen Dimitrij Ahasverov, ki je bil psevdonim Antona Askerca. Prim. Anton Aškerc, Zbrano delo, 1951, II, op. str. 506; Boršnik M., Ašker¿eva bibliografija, ¿ZN, 1935, XXX, 54. 
sklene instrumentalni uvod in s predtaktom uvaja pevski del: prvi, A del, obsega osem taktov in tri takte klavirske poigre ter poteka $\mathrm{v}$ osnovni tonaliteti. Oblikovno je ta del osemtaktna perioda $\mathrm{z}$ jasnim vzponom in padcem. V drugi poiovici 7. takta oz. v 8. taktu je kratek izmik v a-dur. Tudi $\mathrm{v}$ tem, prvem delu, nastopa ton eis ( $\mathrm{v} 10$. taktu) in $\mathrm{s}$ tem reminiscenca na zgoraj omenjeno lestvico. Klavirska spremljava je samostojna, s komplementarnim ritmom, in dobro dopolnjuje melodijo oz. vsebino. Enak ritem je tudi $v$ tritaktni poigri. Drugi, B del (z oznako meno mosso), je sestavljen iz $4+8$ taktov ter dvema taktoma klavirske poigre. Prvi stirje takti začnejo v d-duru ( $\mathrm{Tp}$ osnovne tonalitete), nakar sledi prehod prek a-dura $\mathrm{v}$ h-dur (gibanje glasov poteka v načinu korala). V 19. talitu je osemtaktni recitativni del, ki se melodično in harmonsko logično razvija, spremljava pa je $\mathrm{v}$ tem odstavku tipično recitativna $\mathrm{v}$ smislu opernega recitativa accompagnata, kar predstavlja kontrast prvemu in tudi drugim delom skladbe in nekoliko rahlja vtis celovitosti. Začenja $v$ h-duru, $\mathrm{v}$ 19. taktu; 21. takt je $\mathrm{v}$ d-duru, sledi prehod $\mathrm{v} 22$. in 23. taktu prek plagalne kadence $\mathrm{v}$ cis-dur. $\mathrm{V}$ 26. taktu kadencira $\mathrm{v}$ gis-duru (na dominanti cis-dura). V dveh taktih klavirske poigre preide - preko dominante $\mathrm{v}$ a-durovo tonaliteto, $\mathrm{v}$ kateri prične tretji, $\mathrm{C}$ del.

C del, z oznako allegro, uvaja devetosminski takt (prejšnja dva sta v štiričetrtinskem) z dosledno uporabo osmink v spremljavi. Obsega šest. najst oz. sedemnajst taktov. Modulacije so $\mathrm{v}$ tem delu bogate: $\mathrm{z}$ dominantnim septakordom ( $\mathrm{v}$ 33. taktu) nastopi prehod $\mathrm{v}$ h-mol, $\mathrm{v} 35$. taktu sledi kratek izmik $\mathrm{v}$ fis-mol in nato kadenca ( $\mathrm{v} 36$. in 37. taktu) $\mathrm{v}$ cis-mol; 40. in 41. takt sta $\mathrm{v}$ cis-durovi tonaliteti, ki preide $\mathrm{v} 42$. taktu $\mathrm{v}$ d-dur, nato pa $\mathrm{v}$ 43. taktu $\mathrm{v}$ fis-mol in iz tega $\mathrm{v} 45$. in 46. taktu $\mathrm{v}$ istoimenski fis-dur, kar je dominanta osnovne tonalitete h-mola.

S 47. taktom, z oznako tempo I, začne zadnji del samospeva, ki je v bistvu variirana ponovitev prvega $A$ dela, torej $A$ I. V njem so enake značilnosti $\mathrm{v}$ harmonskem in formalnem oziru. Po sklepu A I dela, v 55. taktu, so še štirje takti klavirske poigre $z$ oznako meno mosso, $v$ katerih pa je kot reminiscenca $\mathrm{v}$ dveh oz. treh taktih tudi pevski glas. Formalna shema samospeva je A B C AI.

Samospev Ciganka Marija štejemo med najboljše stvaritve, ki jih je skladatelj napisal $\mathrm{v}$ tej kompozicijski vrsti. Je na ravni evropskih romantičnih samospevov, odlikuje ga izvirna melodika, jasna oblika in enako jasna harmonska struktura. $\mathrm{V}$ drugem, recitativnem delu, prehaja $\mathrm{v}$ različne tonovske načine, vendar povsem logično in $v$ smislu stopnjevanja, kot ga zahteva vsebina teksta, kar prispeva jasnosti forme. Globoko doživeta vsebina celotne Aškerčeve pesmi, ki jo skladatelj tolmači naravno in neprisiljeno, je dokaz njegove nadarjenosti za to tipično romantično glasbeno formo.

Pri samospevu Ven v mrak in vihar, je zanimiva že izbira teksta Mihaila Lermontova v prevodu Otona Zupančiča. Besedilo je zahtevno, s kontrastno vsebino, ki skladatelja kar vodi v prekomponirano obdelavo. Vendar pa se skladatelj tudi tu ni odmaknil od čiste forme. 
Štirje takti klavirskega uvoda so sestavljeni iz dvakrat po dveh enakih taktov. Harmonsko so zgrajeni na toniki z zmanjšanim septakordom na VII. stopnji. Nadaljnja dva takta prinašata kadenco $v$ h-molu: tonični sekstakord, subdominanta, dominantni nonakord, tonika. že $\mathrm{v}$ uvodu je nakazan dinamičen kontrast, $s$ katerim uvaja skladatelj razpoloženje, ki je značilno za ves samospev. V 5. taktu pričenja pevski del, ki je v prvih dveh taktih oblikovan na harmonskih postopih, omenjenih $\mathrm{v}$ uvodnih taktih klavirskega uvoda. Pripomniti je treba, da skladatelj v tem samospevu ne podvaja pevskega glasu s klavirsko spremljavo, kar je skladbi $\mathrm{v}$ prid; ta obsega na ta način dva samostojna elementa, ki sta med seboj sicer notranje povezana, formalno pa vsak za sebe popolna.

Skladba se z izjemo nekaj izmikov odvija v h-molu. Pogostna je uporaba ostinatnega basa, npr. od 5. do 9. takta, v katerem je zmanjšani septakord $\mathrm{v}$ e-molu, torej subdominanta, ki se $\mathrm{v} 10$. taktu razveže $\mathrm{v}$ tonicni trozvok e-mola; 11. in 12. takt prinašata $\mathrm{v}$ sekvenčnem redu zmanjšani septakord $\mathrm{v}$ a-molu, ki mu sledi d-durova tonaliteta. $\mathrm{V}$ 13. taktu pricenja kadenciranje $\mathrm{v}$ h-molovo tonalteto, $\mathrm{v}$ drugi polovici 15. takta je dvojna dominanta; $v$ 20. taktu je ponovno h-mol, nato pa v 21. taktu dominanta e-mola, ki se $\mathrm{v}$ istem taktu razveže $\mathrm{v}$ tonični sekstakord e-mola (ta predstavlja pravzaprav subdominanto $h$-mola). V 24. taktu pevska linija preneha in sicer $\mathrm{v}$ h-molu, sledijo štirje takti klavirske poigre $\mathrm{s}$ kadenciranjem $\mathrm{v}$ h-molovi tonaliteti (ta del je označen $\mathrm{z}$ dvojno crto).

Drugi del skladbe začenja ponovno $\mathrm{v}$ h-molu in je melodična ter harmonska repriza prvega dela, le vsebina teksta je različna. Gre torej $\nabla$ bistvu za kiticno formo. V 47. taktu je sklep in obenem začetek zakljuck stirih taktov, ki so identični z uvodom.

Iz analize je razvidno, da je harmonska zasnova samospeva razmeroma preprosta in kaže, da je skladatelj znal tudi s skromnimi sredstvi dosečl velik muzikalni učinek. Spričo bogate invencije nic ne moti, da je skladba zgrajena takorekoč na enem samem oz. dveh akordih. Posebna odlika samospeva je dosledno vodenje vseh glasov, tako da lahko tudi po tej strani ovrednotimo skladbo kot zgledno. Domiseln je tudi razplet melodike in harmonije ter dosleden slog, kar uvršča tudi ta samospev v vrh skladateljevega opusa. $\mathrm{V}$ njem uporablja, $\mathrm{v}$ skladu $\mathrm{z}$ vsebino teksta, tipicăne poznoromantične harmonske postope (npr. zmanjšan septakord), vendar na enostaven način, tako da veje iz celotne skladbe pristno romanticno vzdušje.

Samospevi, o katerih je govora $\mathrm{v}$ tem sestavku, sodijo med najboljsa Ipavčeva dela te vrste in pomenijo višek njegovega umetniškega izraza. Odlikuje jih melodična invencija in pisana harmonska zasnova, ki temelji na alteriranih akordih, bogatih modulacijah in izmikih. Skladatelj je globoko doživljal vsebino teksta ter izhajal iz njenega osnovnega razpoloženja, ki ga je glasbeno upodobil naravno, neprisiljeno. Tako se je približal prekomponirani obdelavi. Formalna shema je večinoma jasna in logična. Pri tem se vsiljuje komparacija s Serenado za godala, ki je pomenila $\mathrm{v}$ tistem casu tehten prispevek $\mathrm{k}$ slovenski glasbeni tvornosti in še do danes ni izgubila na svoji kvaliteti. V njej gre za lep primer so- 
glasja med romantično vsebino in klasicistično formo. Omenjeno težnjo po ravnotežju med vsebino in ojliko zasledimo, z majhnimi izjemami, pri vseh skladateljevih stvaritvah. V samospevih Mak žari in Pozabil sem mnogokaj dekle je še omembe vredna klavirska spremljava, ki je tako izdelana, da bi se lahlro izvajala tudi samostojno, medtem ko pevski del brez spremljave ne bi bil popoln - v nasprotju npr. s samospevom C1. ganka Marija, torej $\mathrm{v}$ načinu, ki je bil znacilen za poznoromanticnı sa mospev.

\section{SUMMARY}

The main area of Benjamin Ipavec's creative activity was vocal music. It was especially the lieder in which he developed his creative dispositions and compositional knowledge. Using mostly texts of Slovene authors, he persued his determination to implant the result of the European romantic lied into Slovene music. Quite obvious is also his tendency to break through the traditionally narrow framework of his time in which music was above all a handy means for the awakening of national conscience and patrietic feelings. In this sense Slovene music owes a great deal to B. Ipavec for its qualitative growth during that period. The article deals with the composer's later lieder, written at a point when he had already formed his artistic credo and entered the last phase of romantic style. They rank among his best works and represent the peak of his artistic achievement characterized by marked melodic inventiveness and variegated harmonic structure based on altered chords, rich progressions and modulations. The composer always proceeded directly from the content and the general mood of the text interpreting it in a natural, unrestrained manner, which testifies his talent for this typically romantic musical form. Approaching the durchkomponiert treatment, Ipavec's form is clear and logical and reveals the composer's feeling for congruency between form and content. 